\title{
Diagnosis of growing pains in a Brazilian pediatric population: a prospective investigation
}

\author{
Diagnóstico de dores do crescimento em uma população pediátrica brasileira: uma \\ investigação prospectiva
}

\author{
Luciana Pereira Almeida de Piano ${ }^{1}$, Ricardo Prado Golmia ${ }^{2}$, Andrea Pimentel Fonseca Golmia ${ }^{3}$, \\ Adriana Maluf Elias Sallum ${ }^{4}$, Lucia Akemi Nukumizu ${ }^{5}$, Damião Guedes Castro ${ }^{6}$, Morton Aaron Scheinberg ${ }^{7}$
}

\begin{abstract}
Objective: To establish the clinical aspects of growing pains and to determine, through differential diagnosis, how many patients who referred themselves to a specialized clinic were found to have growing pains. Methods: This study prospectively examined the presence of growing pains in a self-reported population of children and adolescents with signs and symptoms (lower limb pains) of unexplained etiology. Results: A total of 345 children and adolescents were evaluated; 174 (50.4\%) were males and 171 (49.6\%) were females. Three hundred cases were classified as growing pains (87\%). Conclusion: A high frequency of growing pains was found in our study population and it shows that in a prospective evaluation of patients with signs and symptoms of unknown etiology we can find a frequency higher than that reported in literature.
\end{abstract}

Keywords: Pain/etiology; Growth; Lower extremity; Child; Adolescent

\section{RESUMO}

Objetivo: Estabelecer os aspectos clínicos de dores do crescimento e determinar, por meio de diagnóstico diferencial, quantos pacientes com essas dores foram espontaneamente a uma clínica especializada e obtiveram o diagnóstico de dores de crescimento. Métodos: Este estudo analisou prospectivamente a presença de dores do crescimento em uma população de crianças e adolescentes com sinais e sintomas (dores nos membros inferiores) de etiologia desconhecida. Resultados: Foram avaliados 345 crianças e adolescentes; 174 (50,4\%) eram do sexo masculino e $171(49,6 \%)$ do sexo feminino. Trezentos casos foram classificados como dor de crescimento (87\%). Conclusão: Foi encontrada uma elevada frequência de dor de crescimento na população estudada e isso mostra que, em avaliação prospectiva de pacientes com sinais e sintomas de etiologia desconhecida, pode ser encontrada uma frequência maior de dores de crescimento do que a relatada na literatura.

Descritores: Dor/etiologia; Crescimento; Extremidade inferior; Criança; Adolescente

\section{INTRODUCTION}

Recurrent lower limb pains (growing pains) seem to be the most frequent cause of musculoskeletal pain in children. First mentioned in 1823 , the pathophysiological mechanisms surrounding its etiology are still unknown ${ }^{(1)}$. It is a noninflammatory syndrome affecting particularly children between the ages of 5 and 12 years. The child complains of lower limb pain predominantly at night, and its incidence can be as high as $30 \%$ in some clinics when retrospectively evaluated ${ }^{(2)}$.

Some diagnostic criteria have been set up by various investigators to determine its incidence and prevalence, but there are few studies analyzing its incidence on a prospective manner ${ }^{(3)}$. In the absence of well standardized criteria for diagnosis, the true incidence is quite variable in different reports.

\section{OBJECTIVE}

The aim of our study was to evaluate a large number of children with recurrent pain in the lower limbs that were

\footnotetext{
Study carried out at Hospital Abreu Sodré of Associação de Assistência à Criança Deficiente - AACD, São Paulo (SP), Brasil.

'Biomedical professional; PhD in Cardiology; Clinical Research Coordinator at Hospital Abreu Sodré of Associação de Assistência à Criança Deficiente - AACD, São Paulo (SP), Brazil.

${ }^{2}$ Rheumatologist at Hospital Abreu Sodré of Associação de Assistência à Criança Deficiente - AACD, São Paulo (SP), Brazil.

${ }^{3}$ Rheumatologist at Hospital Abreu Sodré of Associação de Assistência à Criança Deficiente - AACD, São Paulo (SP), Brazil.

${ }^{4}$ PhD; Pediatric rheumatologist at Hospital Abreu Sodré of Associação de Assistência à Criança Deficiente - AACD, São Paulo (SP), Brazil.

${ }^{5}$ Pediatric rheumatologist at Hospital Abreu Sodré of Associação de Assistência à Criança Deficiente - AACD, São Paulo (SP), Brazil.

${ }^{6}$ Orthopedic surgeon at Hospital Abreu Sodré of Associação de Assistência à Criança Deficiente - AACD, São Paulo (SP), Brazil.

${ }^{7} \mathrm{PhD}$; Post-doctorate degree; Scientific Director at Hospital Abreu Sodré of Associação de Assistência à Criança Deficiente - AACD, São Paulo (SP), Brazil.

Corresponding author: Luciana Pereira Almeida de Piano - Avenida Professor Ascendino Resi, 724 - Vila Clementino - CEP 04027-000 - São Paulo (SP), Brasil - Tel.: 11 5576-0788 - E-mail: Ipiano@aacd.org.br

Received: Feb 14, 2010 - Accepted: Jul 15, 2010
} 
never assessed until a scheduled visit to an established growing pain (GP) clinic, and to determine through differential diagnosis how many patients who referred themselves to a specialized clinic were found to have GP.

\section{METHODS}

Through internet resources and general letters to primary care health centers, in 8 months, 345 children living in the city of São Paulo were evaluated for the presence of GP. This is a prospective descriptive study in which the selection of the patients was conducted through a questionnaire (survey) given to the patient/ guardians, which contained demographic data (including age, weight, height, and gender) and clinical data (signs and symptoms, co-morbidity, and previous diagnosis). Patients with no conditions presenting signs and symptoms of GP were included.

The current medical status was recorded in charts (physical exam, signs and symptoms of GP, and ordered laboratory and imaging tests). The patients were followed for at least 30 days when they returned for a follow-up visit and reported the results of tests; the diagnosis was established, and when necessary, the patient was referred to other specialties. Patients/guardians provided medical reports in order to document the diagnosis when sent to other specialties. Two pediatricians, one coordinator nurse, one orthopedic pediatrician surgeon, two rheumatologists, and one physiotherapist were part of the evaluating team. The parameters used for the diagnosis of GP were the exclusion criteria outlined by Petersen. We performed a descriptive analysis of the data.

\section{RESULTS}

Of the 345 studied children, 174 (50.4\%) were males and 171 were females $(49.6 \%)$. All evaluated patients had GP and were, therefore, evaluated at the clinic. Three hundred cases were classified as GP (87\%). Details on demographics are presented on Table 1.

Table 1. Demographics of the screened population

\begin{tabular}{lc}
\hline Screened & $\mathbf{n ~ ( \% )}$ \\
\hline All patients & 345 \\
Male & $174(50.4)$ \\
Female & $171(49.6)$ \\
Growing pains & $300(87)$ \\
Withdrawals & $11(3.2)$ \\
Other causes & $34(9.8)$ \\
Mean age (years) (SD) & $9.2(4.0)$ \\
Mean weight (kg) (SD) & $35.7(19.2)$ \\
Mean height (cm) (SD) & $136.9(23.6)$ \\
Mean body mass index (SD) & $18.1(3.9)$ \\
\hline
\end{tabular}

SD: standard deviation.
Table 2 presents details of demographic data of populations with and without GP.

Table 2. Demographics of the population with and without growing pains (GP)

\begin{tabular}{lcc}
\hline Characteristics & With GP $\mathbf{n}(\%)$ & Without GP $-\mathbf{n}(\%)$ \\
\hline Total of patients & 300 & 45 \\
Male & $162(54.0)$ & $12(26.7)$ \\
Female & $140(46.7)$ & $31(68.9)$ \\
Mean age (years) (SD) & $9.2(4.0)$ & $12(3.6)$ \\
Mean weight (kg) (SD) & $36.0(16.9)$ & $44.7(12.4)$ \\
Mean height (cm) (SD) & $136.9(26.1)$ & $148.6(18.5)$ \\
Mean body mass index (SD) & $17.9(4.0)$ & $19.7(3.1)$ \\
\hline
\end{tabular}

SD: standard deviation.

Data on 96 patients who presented pain along with one or more non-GP-related factors and their corresponding diagnoses are shown on Table 3 . Inadequate physical activity was the main cause of GP, followed by congenital foot deformities and other conditions.

Table 3. Other non-GP-related causes of pain

\begin{tabular}{lc}
\hline Causes & $\mathbf{n}(\%)$ \\
\hline Physical exercise & $29(9.7)$ \\
Congenital foot deformities & $20(6.7)$ \\
Scoliosis & $17(5.7)$ \\
Osteochondrosis & $11(3.7)$ \\
Osgood Schlatter disease & $7(2.3)$ \\
Fibromyalgia & $6(2)$ \\
Lordosis & $2(0.7)$ \\
Incidental asymptomatic synovial swelling & $3(1)$ \\
Back pain & $1(0.3)$
\end{tabular}

\section{DISCUSSION}

The prevalence of GP is quite variable in different reports. Our study found a very high frequency of GP, the highest found so far; however, this was the first prospective study using self-referred patients, which may explain some of the results of our study.

Using Petersen's criteria of intermittent pain located in the lower limbs (thigh, calf, and knee muscles), normal physical examination, absence of laboratory abnormalities, and no limitation of activity, after the exclusion of other possible causes, we verified that two thirds of the Brazilian children in our sample were shown to have GP when evaluated prospectively while one third presented other causes ${ }^{(4)}$. The etiology of this disease remains unclear, and ranges from orthopedic problems due to rapid skeletal development, bone and muscular fatigue in active children, and clinical manifestations of a generalized clinical pain syndrome ${ }^{(5)}$. 
Our findings do not differ from prior reports that point toward similar causes, although not necessarily with the same order of frequency. In the current study, it was possible to exclude and give proper directions to a large number of cases in which the diagnosis of GP was ruled out, and proper referrals were given for the specific etiology ${ }^{(4,6)}$.

This is the first prospective study performed so far in which children with leg aches or nocturnal pains were referred for evaluation as a first visit. We believe this may be the reason why our results differ from previously published reports in which the incidence varied from 20 to $40 \%$. Another reason is the fact that in other reports a narrow age range (4-12 years) was used. Another alternative is the fact that compiling results from fixed questionnaires in pediatric clinics can lead to considerable heterogeneity of the obtained data. As previously outlined on the introduction, our data were not obtained by retrospective evaluation but through the establishment of a specialized clinic for that specific purpose. We found a very high incidence of GP when inflammatory, infectious, post-infectious, traumatic, metabolic, hematological, orthopedic diseases, tumors and benign pathologies that can occur in children were excluded.

Since its first description in 1823, and later, in Bennie's work, in 1894, when the term "growing pains" was coined, the pathogenesis of GP has remained unclear $^{(7)}$. It was initially felt that the pain was related to rapid skeletal development, but various other possible causes have been raised by various investigators as mentioned above. Recently, a new hypothesis has been introduced, which includes insufficient sleep, presence of other painful morbidities, and decreased pain threshold in affected areas ${ }^{(8)}$.

The treatment of GP in our pediatric population did not differ from conventional methods; analgesics, correction of associated causes, implementation of physical measures, and parental orientation were performed. Our study using a prospective evaluation on self- referred patients suggests that GP of unknown etiology can be found at a frequency higher than that reported in literature. The design of this study did not allow a comparison between patients with and without GP, but there seems to be a relationship with weight, height, and body mass index (BMI) in this population. A study directed toward this aspect would be more enlightening. The introduction of a specialized clinic enabled the prospective establishment of the presence of GP in a Brazilian cohort of patients with lower limb pain, but also showed that GP can be properly managed through a multidisciplinary intervention involving rheumatologists, orthopedists, and physiotherapists, rapidly achieving a correct diagnosis and affording the family reassurance of the benign nature of the condition.

\section{CONCLUSION}

A high frequency of GP was found in the population of our study and it was shown that a prospective evaluation on self-referred patients suggests that GP of unknown etiology can be found at a frequency higher than that reported in literature.

\section{REFERENCES}

1. Duchamp M. Maladies de la croissance. In: Levrault FG, editor. Mémoires de Médicine practique. Paris: Jean-Frédéric Lobstein; 1823.

2. Uziel Y, Hashkes PJ. Growing pains in children. Pediatr Rheumatol Online J. 2007:5:5.

3. Peterson H. Growing pains. Pediatr Clin North Am. 1986;33(6):1365-72.

4. Horlé B, Wood CH. Growing pains in children: myth or reality? Arch Pediatr. 2008;15(8):1362-5.

5. Lowe RM, Hashkes PJ. Growing pains: a noninflammatory pain syndrome of early childhood. Nat Clin Pract Rheumatol. 2008;4(10):542-9.

6. Evans AM, Scutter SD. Prevalence of "growing pains" in young children. J Pediatr. 2004;145(2):255-8.

7. Bennie PB. Growing pains. Arch Pediatr. 1894;11:337-47.

8. Hashkes PJ, Friedland O, Jaber L, Cohen HA, Wolach B, Uziel Y. Decreased pain threshold in children with growing pains. J Rheumatol. 2004;31(3):610-3. 